\title{
BIOGAS AND BIODIESEL: FUELS FOR THE NEW MILLENNIUM
}

Jitendra Prakash*

\begin{abstract}
The rapid depletion of fossil fuels and their adverse effect on the environment have led scientists to look for alternative sources and technologies of energy production. India took the lead in utilising biological wastes for the production of 'biogas' with varied applications like cooking and power generation. South Africa first used transesterified vegetable oil as 'biodiesel' to power vehicles. With the numerous benefits to mankind and environment, the use of biological fuels is gaining momentum throughout the world. With a little more streamlining, biofuels will be soon replacing the existing fuel sources, at the same time helping us to rectify the thoughtless exploitation of the past.
\end{abstract}

\section{Introduction}

During the past quarter of a century, a significant thrust has been given to the development, trial and induction of a variety of renewable energy technologies for use in different sectors. Experiments 46 carried out in Brazil, China, India and other developing countries have 46 shown that it is possible to associate or 
integrate energy production through biotechnological means with agriculture and industry. Biomass supplies approximately $14 \%$ of mankind's energy, most of it in the

* The author is: Chairman, Biotechnology and Eco Development Research Foundation and President, In Vitro International Pvt. Ltd., Bangalore. 
developing countries. Since photosynthesis produces energy in the amount of almost ten times the world energy consumption, it could in principle supply energy for the whole world population. But due to inexpensive exploitation of fossil fuels there was till date neither the need nor commercial interest for biomass utilization. More recently, due to threat of global warming resulting from increased carbon dioxide emissions, the high subsidies for nuclear energy and uncertainties over oil supply, efforts all around the world are being concentrated to turn biomass as a commercial energy and raw material source.

Renewable sources of energy from plants, wind, tides, waves, water and sun are being explored in order to conserve the dwindling oil resources and to reduce the pollution caused by the burning of fossil fuels. The developed countries of the world and the leading industrial nations are constantly on the lookout for cleaner alternatives to burning oil, gas and coal. But many of the techniques developed to extract energy from renewable resources are not sufficiently advanced to generate and deliver large amounts of energy as quickly and cheaply as fossil fuels. Non conventional sources of solar, tidal and wind energy are not dependable because of geographical locations and seasonal variations. The high costs of building and installing the infrastructure necessary for harvesting energy form the above-mentioned sources have led scientists turn to biological sources to satisfy the energy needs. The energy industry terms this as 'biofuel', which can either be burnt to make steam or heat or turned into gas using different techniques. Two important biofuels viz. biogas and biodiesel have been dealt with in detail in this article.

\section{Biogas}

The generation of biogas, which is a mixture of methane and carbon dioxide, has long been recognized as a rural biotechnological effort. The relevance of biogas technology for developing countries like India lies in the fact that it makes the best possible use biological wastes such as cattle dung for producing clean cooking fuel and fertilizer. Large-scale adaptation of this technology can result in several additional benefits like general improvement in health and hygiene, reduction of human drudgery, creation of local employment and above all, an improvement in the quality of life in rural areas.

In India, the construction of large-scale biogas plants began in the mid-seventies and the process became consolidated with the advent of the National Project on Biogas Development (NPBD) in 1981 and has been continuing since. Against the estimated potential of 12 million biogas plants, 2.9 million family type and 2700 community and institutional have already been set up. This is estimated to have helped in saving 3 million tons of fuelwood per year and manure 
containing nitrogen equivalent to 0.7 million tons of urea. But the potential is much mote in terms of total dung that is available in the country. The bovine population in India is 260 millions, An adult bovine produces an average of 10 $\mathrm{kg}$ of dung per day. Since grazing is a common practice in India, all the dung produced cannot be collected. If it is assumed that $75 \%$ of the dung is collected, nearly 2 millions tons of dung would be available everyday. At $25 \mathrm{~kg}$ per one cubic meter, this dung can feed as many as 40 millions biogas plants of 2 cubic meter capacity, which can be considered the ultimate potential for biogas technology. If other kinds of organic matter such as kitchen waste, water hyacinth and poultry waste could be efficiently used to generate methane, the potential for biogas generation could be virtually unlimited. Human waste too is an excellent source of biogas, which would enhance the potential substantially. With such high potential, biogas can make a significant contribution to the development of small industries and agriculture, and thus to the overall advancement of the rural areas in the developing countries.

\section{Synthesis}

Biogas production is a chemical process occurring in three basic stages during which different bacteria act upon the organic mailer resulting in the formation of methane and acids. The organic matter may be crop residue, kitchen waste or cow dung. The anaerobic digestion starts with the first group of microorganisms acting on the organic material, which is in turn used by the second group of organisms to form organic acids. Methanogenic (methaneproducing) anaerobic bacteria finally utilize these acids for biogas formation. Biogas produced in anaerobic digesters consists of combustible methane (50\%-80\%), carbon dioxide (20\%-50\%), and trace levels of other gases such as hydrogen, carbon monoxide, nitrogen, oxygen, and hydrogen sulfide. The relative percentage of these gases in biogas depends on the feed material and management of the process.

The main factors that influence the rate of digestion and biogas production are $\mathrm{pH}$ (level of acidity) of the organic matter and temperature. It has been well established that a biogas plant can function optimally at $\mathrm{pH} 7$ or just above (neutral solution) and a temperature of around $35^{\circ} \mathrm{C}$. The $\mathrm{pH}$ is self-regulating in most cases. Bicarbonate of soda can be added to maintain a consistent $\mathrm{pH}$. Occasional mixing or agitation of the digesting material can aid the digestion process. Anaerobic bacteria can endure temperatures ranging from below freezing to above $135^{\circ} \mathrm{F}\left(57.2^{\circ} \mathrm{C}\right)$. The mesophilic bacteria thrive at $98^{\circ} \mathrm{F}$ $\left(36.7^{\circ} \mathrm{C}\right)$, while the thermophilic bacteria thrive at $130^{\circ} \mathrm{F}\left(54.4^{\circ} \mathrm{C}\right)$. Decomposition and biogas production occurs more rapidly in the thermophilic range than in the mesophilic range. At low temperatures, bacterial activity slows down resulting 
in substantial decrease in gas generation, which ceases completely below $10^{\circ} \mathrm{C}$. To optimize the digestion process, the digester must be kept at a consistent temperature, as rapid changes will upset bacterial activity.

Carbon-Nitrogen $(\mathrm{CN})$ ratio of the feed material is also an important factor and should be in the range of 20:1 to 30:1. Cowdung, which has a $\mathrm{CN}$ ratio of $25: 1$, is ideal for maximum gas production. Solid concentration in the feed material is also crucial to ensure sufficient gas production, easy mixing and handling. Around $8-10 \%$ of total solids is the normal requirement. Cowdung has a solid concentration of about $20 \%$. It is, therefore, recommended that dung and water be mixed in the ratio of 1:1 to attain the desired level of solids. Hydraulic Retention Time (HRT) is the number of days the feed material is required to remain in the digester to begin gas production. HRT is the most important factor in determining the volume of the digester, which, in turn, determines the cost of the plant. The larger the retention period, higher the construction cost. In India, different HRTs are recommended for three different temperature zones (Table 1). One kilogram of dung can produce about 40 litres of biogas. A biogas plant of two cubic meters would require 50 $\mathrm{kg}$ of dung and equal amount of water to produce 2,000 litres of gas per day. This amount of gas would be sufficient to meet the daily cooking requirement of a family of $4-5$ members.

\section{Biogas plant design}

The biogas plants or digesters are made of concrete, steel, brick, or plastic. They are shaped like troughs, basins or ponds, and may be placed underground or on the surface. All the designs incorporate the same basic components: a premixing area or tank, a digester vessel, a system for using the biogas, and a system for distributing or spreading the effluent.

Butch-type digesters: These are the simplest to build. Their operation consists of loading the digester with organic materials and allowing digestion to take place. The retention time depends mainly on temperature. Once the digestion is complete, the effluent is removed and the process is repeated.

Continuous type digesters: Organic material is constantly or regularly fed into these digesters. The material moves through the digester either mechanically or by the force of the new feed pushing out digested material. Unlike as in the batch-type digesters, continuous digesters produce biogas without the interruption of loading material and unloading effluent. They are hence better suited for large-scale operations. Continuous digesters in turn are of three types viz. vertical tank systems, horizontal tank or plug-flow systems, and multiple 
Table 1. Hydraulic Retention Time (HRT) of the different temperature zones of India

\begin{tabular}{l|c|c|l}
\hline Zone & $\begin{array}{c}\text { Average Ambient } \\
\text { Temperature }\end{array}$ & HRT (days) & Regions \\
\hline I & $>200 \mathrm{C}$ & 30 & $\begin{array}{l}\text { Andhra Pradesh, Karnataka, } \\
\text { Kerala, Maharashtra, Tamil } \\
\text { Nadu, Pondicherry, Goa, } \\
\text { Andaman and Nicobar islands }\end{array}$ \\
\hline II & $15-200 \mathrm{C}$ & 40 & $\begin{array}{l}\text { Bihar, Gujarat, Haryana, } \\
\text { Madhya Pradesh, } \\
\text { Orissa, Punjab, Rajasthan, } \\
\text { Uttar Pradesh, } \\
\text { West Bengal, Jammu. }\end{array}$ \\
\hline III & $<150 \mathrm{C}$ & 55 & $\begin{array}{l}\text { Himachal Pradesh, Kashmir, } \\
\text { hilly areas of Uttar Pradesh, } \\
\text { Sikkim and } \\
\text { other North Eastern states }\end{array}$ \\
\hline
\end{tabular}

Source: TERI (1994)

tank systems. Proper design, operation and maintenance of continuous digesters will facilitate a steady and predictable supply of usable biogas.

\section{Uses and advantages of biogas}

Biogas technology makes optimal utilization of the valuable natural resources and biological wastes.

Biogas can be used for a variety of applications, such as cooking, lighting, motive power and electricity production.

Biogas is cheap and extremely convenient. It is a valuable fuel in the rural areas where the commercial fuels like kerosene and LPG, have severe supply constraints and where biomass is the chief source of fuel.

The effluent or slurry that comes out of biogas plant after the gas is produced is rich in nutrients such as ammonia, phosphorus, potassium, and a number of other trace elements. Therefore, it can be used as an organic manure and conditioner in the fields to augment soil fertility. It can also be used as a livestock feed additive when dried. 
Based on the effective heat produced, a 2 cubic meter biogas plant could replace, in a month, fuel equivalent of $26 \mathrm{~kg}$ of LPG (nearly two standard cylinders), or 37 liters of kerosene, or $88 \mathrm{~kg}$ of charcoal, or $210 \mathrm{~kg}$ of fuelwood, or $740 \mathrm{~kg}$ of animal dung.

Biogas stove has an efficiency of about $55 \%$, which is Comparable to that of a LPG stove. Besides, cooking on biogas is free from smoke and soot, and can substantially reduce the health problems, which are otherwise quite common in most rural areas.

Biogas can partially replace diesel to run Internal Combustion (IC) engines for water pumping and small industries like flour mill, saw mill, oil mill, etc. This would not only reduce dependence on diesel, but also help in reducing carbon pollutants, which adversely affect the atmosphere. Dual — fuel engines $(80 \%$ biogas and $20 \%$ diesel) are now commercially manufactured in India.

The shift to biogas from fossil fuels would result in less dependence on natural resources such as forests, and help check their indiscriminate and unsustainable exploitation.

Since dung is collected systematically for use in biogas, environment can be kept clean and hygienic.

Biogas plants are decentralised systems, which can be installed even in remote areas with very low investments as against centralised thermal power plants and fertilizer factories, which require huge capital investments.

\section{Disadvantages of biogas}

The main hurdles in implementing biogas technology in rural areas are economical and technical in nature. Biogas may be cheaper than LPG or other commercial fuels, but is not so, when compared to traditional fuels like dung cake or crop residue. Fuel for cooking is seldom purchased in rural areas. Viewing from this angle, biogas would be an expensive option. Though attractive incentives such as soft loans and subsidies are being provided by the Government, there does not seem to be adequate motivation for the average farmer to install biogas plants.

The technical problems related to biogas plants mainly emanate from inadequate research inputs. The construction and operation of biogas plants is a fairly established process but it is not developed to the same degree as other commercial technologies. For example, a rigorous chemical reactor design approach is not adopted in the design and optimisation of biogas plants. Fall of gas production in winter months, low burner efficiencies and faulty construction methods leading 
to structural failures are some of the other problems, which are yet to be effectively solved.

\section{Biodiesel}

Biodiesel is the fuel derived from renewable biological resources such as new and used vegetable oils derived from crops such as soyabeans, canola, corn and sunflowers, animal fats and recycled restaurant greases and cooking oil, for use in diesel engines. Tall oil, produced from wood pulp waste, is another feedstock source. Chemically, biodiesel is referred to as the mono alkyl esters of long chain fatty acids derived from renewable lipid sources.

As early as 1900, Rudolf Diesel demonstrated that a diesel engine could run on peanut oil. However, the use of vegetable oil as a fuel attracted little attention except in times of crisis such as during World War II and the energy shortages of the 1970s. The name "biodiesel" was given to transesterified vegetable oil to describe its use as a diesel fuel.

One of the first uses of transesterified vegetable oil was powering heavy-duty vehicles in South Africa before World War II, The increasing environmental concerns and expensive overproduction in agricultural sectors have resulted in extensive testing and usage of biodiesel. Biodiesel is currently being manufactured on a commercial basis by a few large companies but can also be made on a small scale with simple technology.

\section{Synthesis}

The process by which vegetable oil is converted into biodiesel is called transesterification. Transesterification experiments were conducted as early as 1853 , by the scientists E. Duffy and J. Patrick. In the above-mentioned process, a triglyceride molecule or a complex fatty acid is neutralized and an alcohol is ester is created after removing the glycerin. This is accomplished by mixing methanol with sodium hydroxide to make sodium methoxide. The resulting liquid is then mixed into vegetable oil. When the entire mixture settles, glycerin is left on the bottom and methyl esters, or biodiesel, is left on top. The methyl esters is washed and filtered. The resulting biodiesel can be used directly or blended with petroleum diesel for running a diesel engine. Another biodiesel production process not widely in use involves cold-pressed rapeseed oil, which does not produce the glycerin by-product.

\section{Uses and advantages of biodiesel}

Biodiesel is an environmentally friendly alternative to petroleum diesel having lower emission profiles, It is a clean burning fuel, which can run any unmodified 
diesel engine and contributes to the longevity and cleanliness of diesel engines (Specifications are given in Table 2).

Table 2. Standard specifications of diesel and biodiesel

\begin{tabular}{lcc}
\hline Fuel Property & Diesel & Biodiesel \\
Fuel standard & ASTM D975 & ASTM PS121 \\
Fuel composition & C10-C21 HC & C12-C22 FAME \\
Lower heating value, Btu/lb & 130,250 & 120,910 \\
Kinetic viscocity at 400C & $1, .3$ to 4.1 & 1.9 to 6.0 \\
Specific gravity kg/L at 600F & 0.85 & 0.88 \\
Density, lb/gal at 150C & 7.079 & .7 .328 \\
Water ppm by wt & 161 & 0.05 per cent max \\
Carbon, wt per cent & 87 & 77 \\
Hydrogen, wt per cent & 13 & 12 \\
Oxygen, by difference, wt per cent & 0 & 11 \\
Sulphur, wt per cent & 0.05 max & 0 \\
Boiling point, OC & 188 to 333 & 182 to 338 \\
Flash point, OC & 60 to 80 & 100 to 170 \\
Cloud point, OC & -15 to 5 & -3 to 12 \\
Pour point, OC & -35 to-15 & -15 to 16 \\
Cetane number & 40 to 55 & 48 to 60 \\
Autoignition temperature, OC & 316 & 13.8 \\
Stoichiometric air/fuel ratio, wt/wt & 15 & $>7000$ \\
BOCLE scuff, g & 3600 & 314 \\
HFRR, microns & 685 & \\
\hline & & \\
\hline
\end{tabular}

Adapted from Nagin Chand (2002)

Being more viscous than conventional diesel, biodiesel is more lubricating and, therefore, helps in increasing the life of engines.

It is nontoxic and essentially free of sulfur and aromatics and, therefore, safe to handle. 
Pure biodiesel is biodegradable. It degrades as fast as and is as safe as sugar in the environment. When blended with diesel, it accelerates the degradation of diesel to three times the normal rate.

Pure biodiesel has low aquatic toxicity. This characteristic substantially reduces the impact of accidental spills and makes it ideal for use in environmentally sensitive areas like inland waterways.

Biodiesel can reduce all forms of air pollution like air toxics and cancer causing compounds. Pure biodiesel can reduce cancer risk by $94 \%$.

As biodiesel is manufactured from recycled vegetable oils, it helps in conserving resources and makes the best possible use of materials that may be perceived as having little or no negative value.

Biodiesel reduces carbon dioxide emissions by up to $100 \%$, as it is a renewable fuel. This is of great significance as carbon dioxide contributes to $50 \%$ of the Greenhouse Effect.

Biodiesel has a higher flash point or ignition temperature (of about $300 \mathrm{~F}$ ) compared to that of petroleum diesel fuel (flash point of $125 \mathrm{~F}$ ), which makes it safer to transport.

Since biodiesel has relatively low emissions, it is an ideal fuel for use in confined areas such as mines where ventilation is a concern. It can also be safely used in sensitive environments such as marine areas, national parks, forests and heavily polluted cities.

A secondary benefit of biodiesel production is that it creates more employment, as it is three to six times more labour intensive per unit of production than fossil fuels.

For 100 units of biodiesel fuel produced, 11 units of glycerin is formed as byproduct. Glycerin is used in products such as hand creams, toothpaste and lubricants.

\section{Disadvantages of biodiesel}

The major disadvantage of using biodiesel is the high production costs involved. Although recycled waste oils can be used to reduce costs, these sources present problems in production and usage. For example, waste-frying oil is often hydrogenated, which increases its pour point significantly. The search is, therefore, on for lower cost processes and use of the by-products formed. 
Biodiesel has a higher viscosity than the conventional diesel fuel and, therefore, is less useful at lower temperatures. This limits its use in Canada, the northern U.S. and many parts of Europe. In the above-mentioned areas, biodiesel is marketed as an additive in a $5-10 \%$ blend with conventional diesel fuel.

Most biodiesel is currently made solely from soyabean oil, a commodity whose price can fluctuate based on the success of the soya bean production. The price of biodiesel is hence a temporary barrier to its successful commercialisation. Efforts are underway to address this problem from several angles.

\section{The future}

Active research on biofuels is being carried out in different countries. Many of the paper mills in the US, Finland, Scotland and Sweden are already burning wood waste to provide for steam and electricity. Sweden is thinking of growing large 'energy' forests to feed power stations. In Spain, researchers are planning to grow algae in large quantities in the sea, which could be harvested and burnt as fuel or used to make gas. The Portuguese have set up a biomass research centre to study traditional fuels. In Brazil and Kenya, ethanol derived from sugarcane is used as a petroleum supplement or alternative. In Canada, Switchgrass (perennial grass of the millet family) has attracted attention as a fibre source for biofuel since it will typically result in lower ash content than other fibre sources. Ethanol is a biofuel widely in use in the US as a partial gasoline replacement. Research efforts are on to develop an 'improved process for utilizing cellulases to convert cellulose in the agricultural residues such as wheat straw to fermentable sugar, which then can be fermented to ethanol using optimised micro-organisms. Some soil micro-organisms use enzymes that contain iron and vanadium, elements naturally present in soil, to convert nitrogen in the atmosphere into a form which plants can use for growth. The hydrogen that is produced in this process is not used by the plants. It could be collected and put to use as a biofuel. Moreover, the bacteria that use iron in this process could provide clues as to how iron might serve as a catalyst in making nitrogen fertilizers. Current fertilizer production processes (especially ammonia fertilizer) use extremely high temperatures and pressure requiring lots of fossil fuel. Alternative processes using biofuels could lower costs and preserve fuel.

There is urgency felt all over the world to find and exploit alternative fuels. The attempt to exploit renewable sources of energy should be understood in the light of the recent global crises and uncertainties arising out of the international scene. The main challenge faced by the industry is to increase the awareness of potential consumers of the merits of biofuels. The most immediate need is to develop cheaper designs of biofuel plants. One possible approach is to try 
different materials for construction, which would result in cost reduction without compromising on durability. Efforts are also on to arrive at the best combination of chemical and mechanical additives to optimise the emission benefits of biofuels. It is necessary to make sure that biofuels are easily available at prices competitive in the market with other alternative fuels and technologies. The traditional sources of energy must be considered as the base and the economic value of biofuels should be set accordingly. In course of time, when traditional energy sources become more expensive, biofuels will gain importance, as they become more cost competitive. To achieve sustainable energy and industrial raw material supply, the fossil fuels - borrowed from the past should be and will be replaced by biofuels.

\section{References}

1. Nagin Chand. 2002. Plant Oils - Fuel of the Future. Journal of Scientific and Industrial Research. 61: 7-16,

2. TERI. 1994. Biogas: A Source of Rural Employment. Tata Energy Research Institute, New Delhi.

3. www.greenfuels.org/bioindex.html 